Jurnal Teknik Hidro

Volume 11 Nomor 2, Agustus 2018

\title{
PENGARUH JUMLAH LUBANG PIPA ISAP FLUSHING COINDUIT SEBAGAI ALAT PENGGELONTORAN TERHADAP VOLUME SEDIMEN DI WADUK (UJI EKSPERIMENTAL)
}

\author{
Mifta Ulfa ${ }^{2)}$ dan Neli Mastra. ${ }^{3)}$ \\ ${ }^{1)}$ Program Studi Teknik Pengairan Universitas Muhammadiyah Makassar, \\ Email : Miftaulfa998@gmail.com \\ ${ }^{2)}$ Program Studi Teknik Pengairan Universitas Muhammadiyah Makassar, \\ Email : Nelimastra@gmail.com
}

\begin{abstract}
Abstrak
Kerusakan Daerah Aliran Sungai (DAS) menyebabkan erosi lahan terhadap besar yang berdampak terhadap angkutan sedimen di sungai. Penelitian ini bertujuan untuk mengetahui pengaruh jumlah lubang pipa isap flushing conduit terhadap penggelontoran sedimen dan untuk mengetahui pengaruh jumlah lubang pipa isap terhadap tekanan isap flushing conduit. Karakteristik sedimen yang digunakan dalam penelitian ini adalah pasir sedang berdasarkan skala wentworth dari hasil analisa saringan. Dari hasil penelitian menunjukkan jumlah lubang pipa isap terhadap volume gelontor untuk 6 lubang pada waktu $(t) 3$ yaitu 0,0035( $\left.\mathrm{m}^{3}\right)$, pada waktu (t) 6 yaitu 0,0038( $\left.\mathrm{m}^{3}\right)$, pada waktu $(t) 9$ yaitu 0,0041 $\left(\mathrm{m}^{3}\right)$. dan untuk 10 lubang pada waktu $(\mathrm{t}) 3$ yaitu 0,0042( $\left.\mathrm{m}^{3}\right)$, pada waktu $(\mathrm{t}) 6$ yaitu $0,0046\left(\mathrm{~m}^{3}\right)$, pada waktu $(\mathrm{t}) 9$ yaitu 0,0054( $\left.\mathrm{m}^{3}\right)$. Dan untuk 14 lubang pada waktu (t) 3 yaitu 0,0064( $\left.\mathrm{m}^{3}\right)$, pada waktu ( $(t) 6$ yaitu 0,0065( $\left.\mathrm{m}^{3}\right)$, pada waktu (t) 9 yaitu $0,0067\left(\mathrm{~m}^{3}\right)$. Kinerja flushing conduit menunjukkan bahwa semakin banyak jumlah lubang pipa isap maka jumlah volume tergenlontor $(\mathrm{Vg})$ cenderung meningkat. Hal ini diakibatkan oleh fluktuasi tekanan relatif cukup besar untuk mengusik dan mengisap endapan sedimen kedalam pipa flushing conduit.

kata kunci : Flushing Conduit, Jumlah lubang pipa isap, Waduk.
\end{abstract}

\begin{abstract}
Damage to water sheds (DAS) causes majos land erosion that impacts sediment transport in rivers. This study aims to determine the effect of the number of flushing conduit suction pipe on the sediment displacement and to determine the effect of the number of suction pipa to suction pressure flushing conduit. Sediment characteristic used in this research is medium sand based on wentwotrh scale from result of filter analysis. The results showed that the number of suction pipe holes on the volume of gelontor for 6 holes at time $(t) 3$ is $0,0035\left(\mathrm{~m}^{3}\right)$, at time $(t) 6$ that is $0,0038\left(\mathrm{~m}^{3}\right)$, at time $(t) 9$ is $0,0041\left(\mathrm{~m}^{3}\right)$. And for 10 holes at time $(t) 3$ is $0,0042\left(\mathrm{~m}^{3}\right)$, at time $(t) 6$ is $0,0046\left(\mathrm{~m}^{3}\right)$, at time $(t) 9$ is 0,0054( $\left.\mathrm{m}^{3}\right)$. And for 14 holes at time $(t) 3$ is 0,0064( $\left.\mathrm{m}^{3}\right)$, at time $(t) 6$ is $0,0065\left(\mathrm{~m}^{3}\right)$, at time $(t) 9$ is $0,0067\left(\mathrm{~m}^{3}\right)$. The performance of flushing conduit shows that the more number of suction pipe holes the amount of volume that is flushed $(\mathrm{Vg})$ tends to increase. This is caused by relatively large relative pressure fluctuations to distrurb and sediment sludge into the flushing conduit pipe.
\end{abstract}

Keywords : Flushing conduit, number of suction pipe, Dam. 


\section{PENDAHULUAN}

Daerah aliran sungai (DAS) adalah suatu wilayah daratan yang secara topografik dibatasi oleh punggungpunggung gunung yang menampung dan menyimpan air hujan untuk kemudian menyalurkan ke laut melalui sungai utama (Chay Asdak, 2010). Kerusakan DAS menyebabkan erosi lahan terhadap besar yang berdampak terhadap angkutan sedimen disungai. DAS merupakan area tangkapan air waduk, tingginya erosi akan menyebabkan transportasi sedimen ke waduk cukup tinggi, sehingga terjadi sedimentasi di waduk.

Penggerukan sedimen di beberapa waduk sudah dilakukan sejak lama namun hasilnya dirasa kurang maksimal. Terbukti dari berbagai hasil penelitian menunjukkan bahwa terjadi pengurangan kapasitas waduk dari tahun ke tahun. Rencana pengerukan (dredging) endapan sedimentasi waduk sangat tidak mungkin. Pengerukan endapan sedimentasi memerlukan biaya yang sangat besar bahkan biaya mobilisasi peralatan (dredging) lebih mahal dibandingkan biaya operasi pengerukan (dredging) (Suroso dan Wahyu Widiyanto,2009).

\section{Proses Sedimentasi}

Proses sedimentasi dapat terjadi pada lahan-lahan pertanian maupun di sepanjang dasar sunga, dasar waduk, muara, dan sebagainya. Berdasarkan proses terjadinya sedimentasi dapat dibedakan menjadi dua bagian yaitu:

a) Proses Sedimentasi secara Geologis (Normal)

Sedimentasi secara geologis merupakan proses erosi tanah yang berjalan secara normal, artinya proses pengendapan yang berlangsung masih dalam batas yang diperkenankan atau dalam keseimbangan alam dari proses degradasi dan agradasi pada perataan kulit bumi akibat pelapukan.

b) Proses Sedimentasi Dipercepat

Sedimentasi yang dipercepat merupakan proses terjadinya sedimentasi yang menyimpan dari proses secara geologi dan berlangsung dalam waktu yang cepat, bersifat merusak atau merugikan dan dapat mengganggu keseimbangan alam atau kelestarian lingkungan hidup. Kejadian tersebut biasanya disebabkan oleh kegiatan manusia dalam mengelolah tanah.

\section{Kapasitas Waduk}

Kapasitas waduk saat direncanakan

berdasarkan perhitungan volume tampungan air tanpa adanya sedimentasi. Seiring berjalannya waktu pengoperasian waduk, terjadi sedimentasi diareal genangan hingga menyebabkan 
berkurangnya kapasitas tampungan waduk itu sendiri.

kapasitas waduk secara umum dibedakan menjadi tiga yaitu :

a) Kapsitas mati (dead storage)

b) Kapasitas pelayanan (Active Storage)

c) Kapasitas total

Umur pelayanan waduk merupakan fungsi dari volume tampungan aktif (Ilyas et al., 1991). Semakin menyusut volume tampungan aktif menandakan semakin pendek umur pelayanan waduk. Pelayanan volume tampungan aktif lebih banyak disebabkan karena bertambahnya volume sedimen yang masuk kedalam waduk.

\section{Dsitribusi Ukuran Butir Sedimen}

Tabel 1. Klasifikasi ukuran butir sedimen \begin{tabular}{ccc} 
menurut & skala & Wentworth \\
\hline Klasifikasi & Diameter partikel $(\mathrm{mm})$
\end{tabular}

\begin{tabular}{|c|c|c|}
\hline \multirow{4}{*}{ Berangkal } & Sangat besar & $4096-2048$ \\
\hline & Besar & $2048-1024$ \\
\hline & Sedang & $1024-512$ \\
\hline & Kecil & $512-256$ \\
\hline \multirow[t]{2}{*}{ Kerakal } & Besar & $256-128$ \\
\hline & Kecil & $128-64$ \\
\hline \multirow{4}{*}{ Koral (Kerikil besar) } & Sangat besar & $64-32$ \\
\hline & Kasar & $32-16$ \\
\hline & Sedang & $16-8$ \\
\hline & Halus & $8-4$ \\
\hline \multirow[t]{2}{*}{ Kerikil } & & $4-2$ \\
\hline & Sangat besar & $2-1$ \\
\hline \multirow{4}{*}{ Pasir } & Kasar & $1-0,5$ \\
\hline & Sedang & $0,5-0,25$ \\
\hline & Halus & $0,25-0,125$ \\
\hline & Sangat Halus & $0,125-0,062$ \\
\hline \multirow[t]{4}{*}{ Lumpur } & Kasar & $0,062-0,031$ \\
\hline & Sedang & $0,031-0,016$ \\
\hline & Halus & $0,016-0,008$ \\
\hline & Sangat Halus & $0,008-0,004$ \\
\hline \multirow{4}{*}{ Lempung } & Kasar & $0,004-0,002$ \\
\hline & Sedang & $0,002-0,001$ \\
\hline & Halus & $0,001-0,0005$ \\
\hline & Sangat Halus & $0,0005-0,00024$ \\
\hline
\end{tabular}

Sumber : Muhammad Arsyad Thaha (2006)

Penggelontoran Sedimen Dengan Metode

Flushing
Prinsip dari metode penggelontoran sedimen dengan energi potensia air waduk (flushing) adalah mengeluarkan sedimen dengan mengambil manfaat energi hidrolik akibat beda tinggi antara muka air di depan dan belakang bendungan, untuk mensuplai energi pada sediment flushing system.

Metode flushing counduit atau pengurasan melalui pipa dengan memanfaatkan fluktuasi tekanan untuk mengusik endapan sedimen sehingga terfluidasi, dan selanjutnya terhisap ke dalam pipa melalui lubang kecil kemudian terjadi transpor endapan sedimen dalam pipa.

\section{Perbedaan Mekanisme kerja Fluidasi}

\section{dengan flushing Conduit}

Tabel 2. Perbedaan metode kerja fluidasi dengan flushing conduit

\begin{tabular}{lll}
\hline No. & \multicolumn{1}{c}{ Metode Fluidasi } & \multicolumn{1}{c}{ Metode flushing conduit } \\
\hline 1. & $\begin{array}{l}\text { Mengendalikan aliran permukaan } \\
\text { mengalirkan sedimen ke daerah } \\
\text { yang lebih dalam }\end{array}$ & $\begin{array}{l}\text { Mengendalikan aliran dalam pipa } \\
\text { untuk menggelontorkan sedimen } \\
\text { ke daerah lebih dalam }\end{array}$ \\
\hline $\begin{array}{l}\text { 2. } \\
\text { mengandalkan pancaran jet lui lubang perforasi untuk } \\
\text { mengusik dan mengangkat } \\
\text { sedimen }\end{array}$ & $\begin{array}{l}\text { Mengandalkan hisapan sedimen } \\
\text { melalui lubang isap ke dalam pipa } \\
\text { dan transpor sedimen dalam pipa }\end{array}$ \\
\hline 3. & Membutuhkan tekanan yang besar & $\begin{array}{l}\text { Membutuhkan tekanan fluktuaktif } \\
\text { yang relatif besar. }\end{array}$ \\
\hline 4. & $\begin{array}{l}\text { Membutuhkan debit yang relatif } \\
\text { besar }\end{array}$ & $\begin{array}{l}\text { Membutuhkan debit yang relatif } \\
\text { besar }\end{array}$ \\
\hline 5. & $\begin{array}{l}\text { Sistem pengaliran dilakukan } \\
\text { dengan pengaliran bebas }\end{array}$ & $\begin{array}{l}\text { Sistem pengaliran dilakukan } \\
\text { dengan pengaliran bertekanan } \\
\text { fluktuatuf }\end{array}$ \\
\hline 6. & $\begin{array}{l}\text { Tekanan dsalam pipa harus lebih } \\
\text { besar daripada di luar pipa }\end{array}$ & $\begin{array}{l}\text { Tekanan dalam pipa harus lebih } \\
\text { rendah dari pada luar pipa }\end{array}$ \\
\hline
\end{tabular}

Sumber : Amrullah (2011)

\section{Aliran Dalam Saluran Tertutup (PIPA)}

Aliran dalam pipa berfungsi untuk memindahkan fluida dari suatu tempat ke tempat yang lain. Pada umumnya fluida 
yang akan dipindahkan memiliki nilai Re=Bilangan Reynold (tak berdimensi)

kekentalan yang berbeda-beda. Nilai $V=$ Kecepatan rata-rata ( $\mathrm{ft} / \mathrm{s}$ atau $\mathrm{m} / \mathrm{s}$ )

kekentalan ini sangat penting untuk $\mathrm{D}=$ Diameter pipa ( $\mathrm{ft}$ atau $\mathrm{m}$ )

diketahui agar dapat menentukan kebutuhan $\quad \mathrm{v}=$ Viskositas kinematik $\left(\mathrm{m}^{2} / \mathrm{s}\right)$

energi yng diperlukan.

Perpindahan fluida (airan atau gas)

Kehilangan energi pada aliran laminer ini terutama disebabkan oleh adanya didalam sebuah saluran tertutup (pipa) kekentalan fluida dan tidak dipengaruhi sangat penting didalam konsep flushing oleh bidang batas atau kekentalan dinding. conduit yang menerapkan penggelontoran Hal ini ditunjukkan dengan persamaan sedimentasi didlam pipa. Faktor-faktor poisouille sebagai berikut : (Triatmadja R., yang mempengaruhi aliran dalam salutan 2008).

tertutup, yaitu keepatan, debit dan luas penampang saluran. Sehingga dapat dirumuskan sebagai berikut:

$$
\begin{aligned}
& Q=A . V \\
& V=\frac{Q}{A}
\end{aligned}
$$

Dimana $: Q=$ Debit aliran $\left(\mathrm{m}^{3} / \mathrm{dtk}\right)$

$\mathrm{A}=$ Luas penampang aliran $\left(\mathrm{m}^{2}\right)$

$\mathrm{V}=$ Kecepatan aliran dalam pipa (m/dtk)

\section{Aliran Laminer dan Turbulen}

Menurut hasil percobaan Reynold, untuk membedakan apakah aliran itu turbulen atau laminer dapat menggunakan bilangan tak berdimensi yang disebut dengan bilangan Reynold. Bilangan ini dihitung dengan persamaan berikut:

$\operatorname{Re}=\frac{p v D}{\mu}=\frac{V D}{v}$

$h_{L}=-f \frac{L \cdot V^{\lambda_{2}}}{D \cdot 2 G}$ dengan $\frac{64}{R e}$

Dimana :

$$
\begin{aligned}
& \mathrm{f}=\text { koefisien gesek Darcy-Weisbach } \\
& \mathrm{v}=\text { kecepatan aliran }(\mathrm{m} / \mathrm{det}) \\
& \mathrm{g}=\text { percepatan grafitasi }\left(\mathrm{m}^{2} / \mathrm{det}\right) \\
& \mathrm{L}=\text { panjang pipa }(\mathrm{m}) \\
& \mathrm{D}=\operatorname{diameter} \text { pipa }(\mathrm{m})
\end{aligned}
$$

\section{Konsep Kriteria Desain Lubang Isap}

Kinerja metode flushing untuk penggelontoran sedimen dipengaruhi salah satu adalah desain diameter lubang isap yang tepat. Sebagai bahan pertimbangan beberapa konsep criteria sebagai berikut :

Semakin besar diameter lubang isap $\left(D_{f}\right)$ potensi masuknya deposit sedimen kedalam pipa lebih besar, Sedimen masuk ke dalam pipa salah satu dipengaruhi oleh adanya fluktuasi tekanan hisap akibat pengejutan debit atau variasi tekanan.

Dimana: 
Semakin besar sedimen yang masuk kedalam pipa diperlukan tekanan aliran untuk menggelontorkan, Diameter lubang isap $\left(D_{f}\right)$ yang lebih besar akan berpengaruh terhadap pengurangan tekanan akibat kehilangan tinggi tekanan relative tinggi, Kombinasi ukuran $\mathrm{D}, \mathrm{D}_{\mathrm{f}}$ dan $\mathrm{d}_{\mathrm{b}}$, a harus menjamin daya isap tekanan flushing conduit yang lebih baik Rasio diameter lubang isap dan diameter pipa flushing $\left(\mathrm{D} / \mathrm{D}_{\mathrm{f}}\right)$ harus dapat menghasilkan kerjasama antar diameter lubang yang efektif dan efisien,Ruang dalam pipa harus selalu bersih dari material seimen dan kotoran, Beberapa kehilangan tinggi tenaga yang terkait dengan bentuk tipe lubang isap harus diperhitungkan.

\section{METODE PENELITIAN}

\section{Lokasi dan Waktu Penelitian}

Penelitian ini dilakukan di Laboratorium Fakultas Teknik Universitas Muhammadiyah Makassar

\section{Jenis Penelitian}

Jenis penelitan yang digunakan adalah eksperimental, dimana penelitian tersebut dibuat dan dirancang sendiri oleh peneliti dengan berpedoman pada literaturliteratur yang berkaitan dengan flushing conduit, serta adanya kontrol dengan tujuan untuk mengetahui sebab akibat dari penggelontoran sedemen serta berapa besar pengaruh penggelontoan terhadap variasi sedimen.

\section{Tahap PenelitianPersiapan}

Studi literatur dilakukan untuk mencari sumber data dan informasi yang akan dimuat sebagai referensi teori dalam melakukan penelitian ini (flushing conduit).

\section{Perancangan Model}

perancangan Model untuk penelitian dilakukan terlebih dahulu untuk mengetahui konsep penelitian (flushing conduit) yang lebih jelas agar dalam penerapan dilapangan dapat berjalan sesuai rencana.

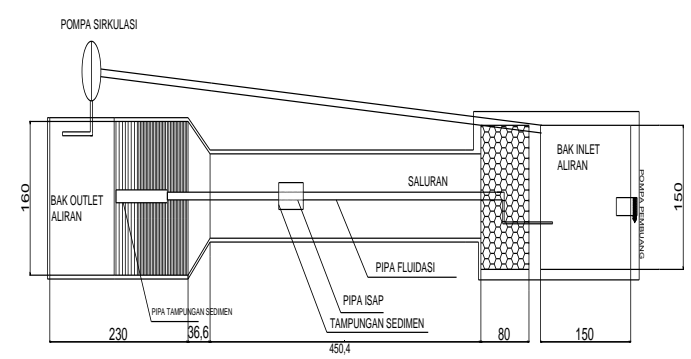

\section{Gambar 1. Denah Flushing Conduit}

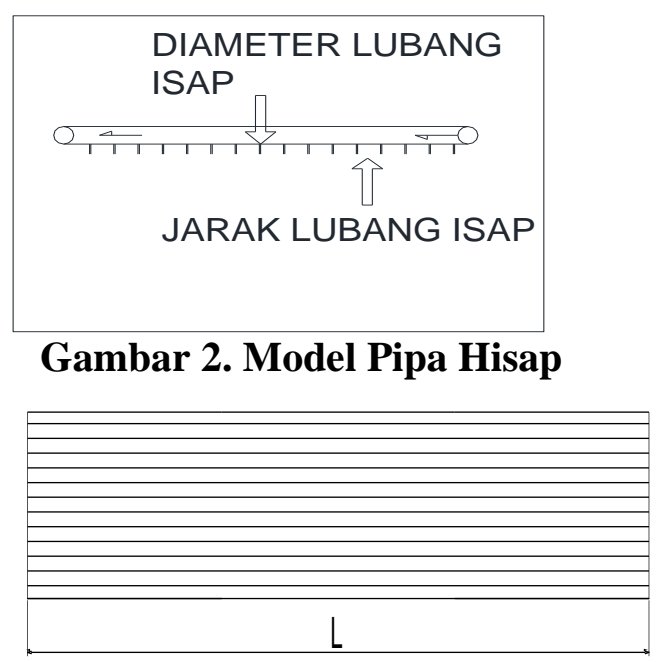

Gambar 3. Model Sedimen

\section{Langkah-Langkah Penelitian}

Langkah-langkah dalam melakukan

percobaan dalam penelitian : 
1) Membuat model untuk pengujian dilaboratorium serta mempersiapkan alat dan bahan yang diperlukan.

2) Merangkaikan susunan bahan dan alat yang akan digunakan mulai dari sistem pompa hidrolik, perpipaan, variabel bebas maupun variabel sesuai perancangan model penelitian.

3) Melakukan simulasi pengujian model seperti sistem pengaliran air dalam pipa oleh pompa hidraulik dan melakukan pengujian dengan pengaliran sedimen dalam pipa.

4) Melakukan percobaan awal dengan menggunakan variabel bebas dan variabel terikat sesuai dengan rumusan masalah yang telah ditentukan, yaitu pengaruh jumlah lubang pipa isap flushing conduit pada penggelontoran sedimen.

5) Menjalankan proses air dengan mengalirkan air dan sedimen dalam pipa sesuai debit dan variasi tekanan yang ditentukan.

6) Mengamati perilaku sedimen yang mulai terisap masuk kedalam pipa untuk digelontor dengan menggunakan manometer, serta stopwatch sebagai alat pengukur tekanan dan waktu.

7) Dari hasil percobaan tersebut, maka data yang perlu dicatat ialah waktu (T), variasi tekanan $(\mathrm{P})$, serta volume sedimen yang tergelontor (vg)

8) Selanjutnya mengukur berapa besar volume sedimen yang digelontor pada setiap masing-masing variasi tekanan yang diberikan.

9) Hasil pengukuran sedimen yang tergelontor menjadi data jumlah sedimen endapan yang tergelontor.

10) Prosedur ii dilakukan dengan beberapa kali percobaan pada variasi tekanan terhadap sedimen yang digelontor sehingga dapat menjadi bahan perbandingan.

\section{Flow Chart Penelitian}

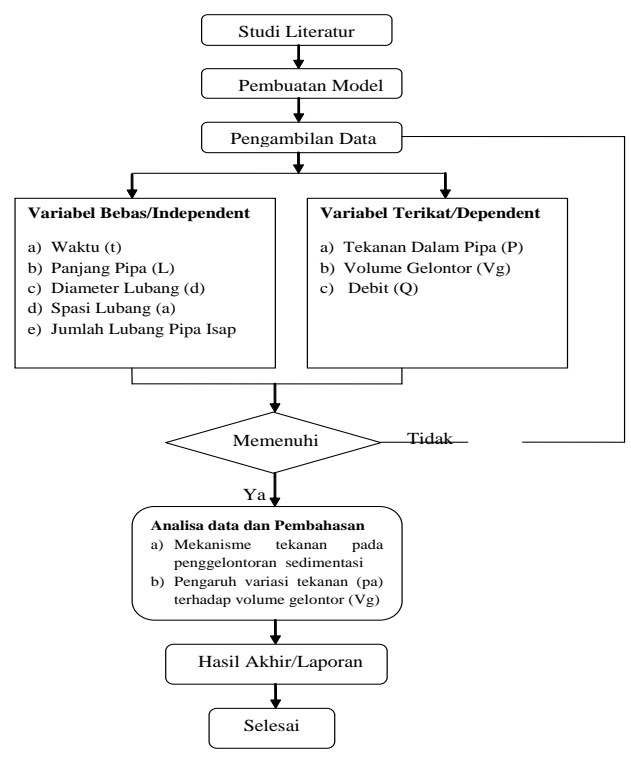

Gambar 4. Flow Chart Penelitian

\section{HASIL DAN PEMBAHASAN}

\section{Karakteristik Sedimen}

Karakteristik sedimen yang digunakan dalam penelitiuan ini adalah Pasir halus, sesuai dengan hasil 
pemeriksaan ukuran butir dengan uji saringan dan gradasi ukuran butir, yang disajikan pada gambar dan tabel berikut.

Tabel 3. Data analisa saringan

\begin{tabular}{cccccc}
\hline \multirow{2}{*}{$\begin{array}{c}\text { Saringan } \\
\text { No. }\end{array}$} & $\begin{array}{c}\text { Diameter } \\
(\mathbf{m m})\end{array}$ & $\begin{array}{c}\text { Berat } \\
\text { Tertahan } \\
\text { (gram) }\end{array}$ & $\begin{array}{c}\text { Berat } \\
\text { kumulatif } \\
\text { (gram) }\end{array}$ & \multicolumn{2}{c}{ Persen (\%) } \\
\cline { 5 - 6 } & & & Tertahan & Lolos \\
\hline 4 & 4.76 & 0 & 0 & 0 & 100 \\
\hline 8 & 2.38 & 118 & 118 & 7.712418 & 92.287581 \\
\hline 16 & 1.19 & 164 & 282 & $1,843,137$ & 81.56862 \\
\hline 30 & 0.595 & 405 & 687 & 44.90196 & 55.09803 \\
\hline 50 & 0.297 & 392 & 1079 & 70.52287 & 29.477124 \\
\hline 100 & 0.149 & 262 & 1341 & 87.6475 & 12.352941 \\
\hline 200 & 0.074 & 189 & 1530 & 100 & 0 \\
\hline Pan & - & & 1530 & 100 & 0 \\
\hline
\end{tabular}

Sumber:Hasil Analisa Saringan

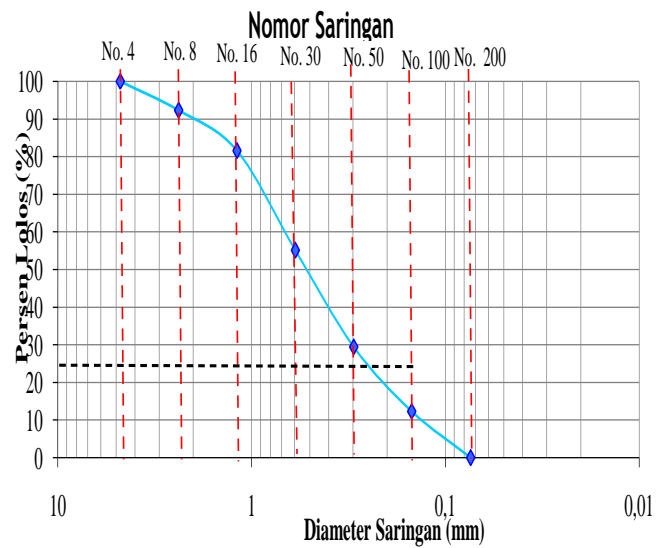

Gambar 5. Gradasi ukuran butiran sedimen (sampel)

Hubungan Antara Jumlah Lubang Pipa Isap Terhadap Volume Gelontor (Vg).

Berdasarkan hasil uraian data-data yang telah diperoleh dari hasil pengujian Flushing Conduit, maka dibuat kajian hubungan antara jumlah lubang pipa isap terhadap volume gelontor (Vg) pada berbagai nilai $(\mathrm{Q})$ dan ketebalan sedimen (db) pada variasi waktu (T) seperti pada gambar dan tabel berikut:

Tabel 4. Hubungan antara jumlah lubang pipa isap terhadap volume gelontor $(\mathrm{Vg})$

\begin{tabular}{|c|c|c|c|}
\hline No & Jumlah Lubang Pipa Isap & $\begin{array}{c}\text { Waktu (t) } \\
\text { (menit) }\end{array}$ & $\begin{array}{l}\text { Volume Gelontor(Vg) } \\
\qquad\left(\mathrm{m}^{3}\right)\end{array}$ \\
\hline 1. & \multirow{3}{*}{6} & 3 & 0.0035 \\
\hline 2. & & 6 & 0.0038 \\
\hline 3. & & 9 & 0.0041 \\
\hline 4. & \multirow{3}{*}{10} & 3 & 0.0042 \\
\hline 5. & & 6 & 0.0046 \\
\hline 6. & & 9 & 0.0054 \\
\hline 7. & \multirow{3}{*}{14} & 3 & 0.0064 \\
\hline 8. & & 6 & 0.0065 \\
\hline 9. & & 9 & 0.0067 \\
\hline
\end{tabular}

Sumber : Hasil Perhitungan

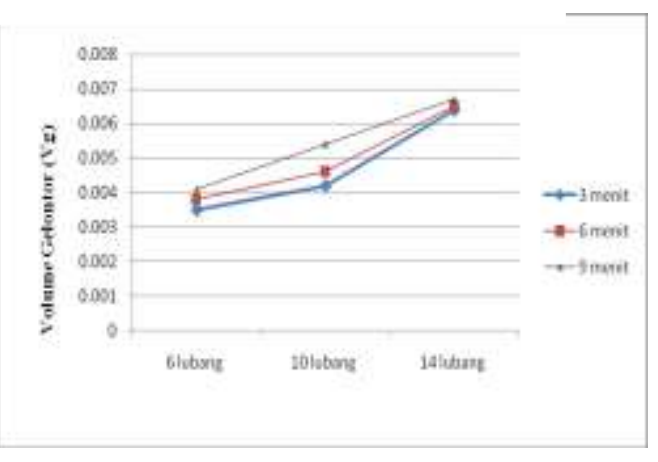

Gambar 6. Grafik hubungan jumlah lubang pipa isap terhadap volume gelontor $(\mathrm{Vg})$ dengan berbagai nilai debit (Q1)

Tabel 5. Hubungan jumlah lubang pipa isap terhadap volume gelontor $(\mathrm{Vg})$

\begin{tabular}{|c|c|c|c|}
\hline $\mathrm{N}_{0}$ & Jumlah Lubang Pipa Isap & $\begin{array}{c}\text { Waktu (t) } \\
\text { (menit) }\end{array}$ & $\begin{array}{l}\text { Volume Gelontor }(\mathrm{Vg} \\
\qquad\left(\mathrm{m}^{3}\right)\end{array}$ \\
\hline 1. & \multirow{3}{*}{6} & 3 & 0.0037 \\
\hline 2. & & 6 & 0.0043 \\
\hline 3. & & 9 & 0.0045 \\
\hline 4. & \multirow{3}{*}{10} & 3 & 0.0053 \\
\hline 5. & & 6 & 0.0058 \\
\hline 6. & & 9 & 0.0065 \\
\hline 7. & \multirow{3}{*}{14} & 3 & 0.0075 \\
\hline 8. & & 6 & 0.0077 \\
\hline 9. & & 9 & 0.0079 \\
\hline
\end{tabular}

Sumber : Hasil Perhitungan

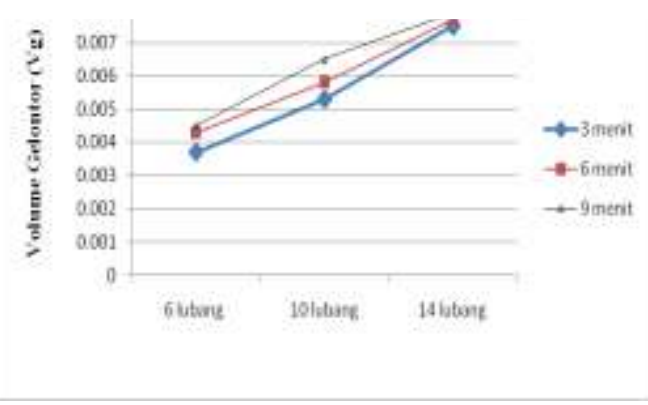


Gambar 7. Grafik hubungan jumlah lubang pipa isap terhadap volume gelontor (Vg) dengan berbagai nilai debit (Q2)

Tabel 6. Hubungan jumlah lubang pipa isap terhadap volume gelontor $(\mathrm{Vg})$

\begin{tabular}{|c|c|c|c|}
\hline $\mathrm{N}_{0}$ & Jumlah Lubang Pipa Isap & $\begin{array}{c}\text { Waktu (t) } \\
\text { (menit) }\end{array}$ & $\begin{array}{l}\text { Volume Gelontor }(\mathrm{Vg}) \\
\left(\mathrm{m}^{3}\right)\end{array}$ \\
\hline 1. & \multirow{3}{*}{6} & 3 & 0.0041 \\
\hline 2. & & 6 & 0.0044 \\
\hline 3. & & 9 & 0.0049 \\
\hline 4. & \multirow{3}{*}{10} & 3 & 0.0059 \\
\hline 5. & & 6 & 0.0059 \\
\hline 6. & & 9 & 0.0067 \\
\hline 7. & \multirow{3}{*}{14} & 3 & 0.0079 \\
\hline 8. & & 6 & 0.0083 \\
\hline 9. & & 9 & 0.0085 \\
\hline
\end{tabular}

Sumber : Hasil Perhitungan

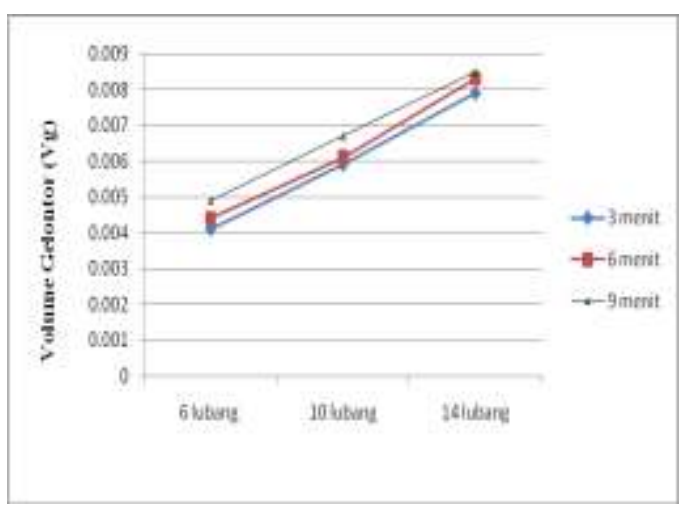

Gambar 8. Grafik hubungan jumlah lubang pipa isap terhadap volume gelontor (Vg) dengan berbagai nilai debit (Q3)

Hubungan Jumlah Lubang Pipa Isap

\section{Terhadap Tekanan (P)}

Berdasarkan hasil uraian maka dibuat kajian hubungan pengaruh jumlah lubang pipa isap dengan tekanan pada volume gelontor ( $\mathrm{Vg}$ ) yang menunjukkan bahwa semakin banyak jumlah lubang pipa isap maka volume gelontor $(\mathrm{Vg})$ semakin besar. Hal ini diperkirakan dipengaruhi oleh tinggi tekanan yang cukup signifikan.

Tabel 7. Hubungan jumlah lubang pipa isap terhadap tekanan $(\mathrm{P})$ untuk Q1.

\begin{tabular}{|c|c|c|c|}
\hline No & Jumlah Lubang Pipa Isap & $\begin{array}{c}\text { Waktu (t) } \\
\text { (menit) }\end{array}$ & Tekanan $(\mathrm{P})$ \\
\hline 1. & \multirow{3}{*}{6} & 3 & 0.05542 \\
\hline 2. & & 6 & 0.05848 \\
\hline 3. & & 9 & 0.06052 \\
\hline 4. & \multirow{3}{*}{10} & 3 & 0.05338 \\
\hline 5. & & 6 & 0.05508 \\
\hline 6. & & 9 & 0.05746 \\
\hline 7. & \multirow{3}{*}{14} & 3 & 0.05304 \\
\hline 8. & & 6 & 0.05372 \\
\hline 9. & & 9 & 0.05474 \\
\hline
\end{tabular}

Sumber : Hasil Perhitungan

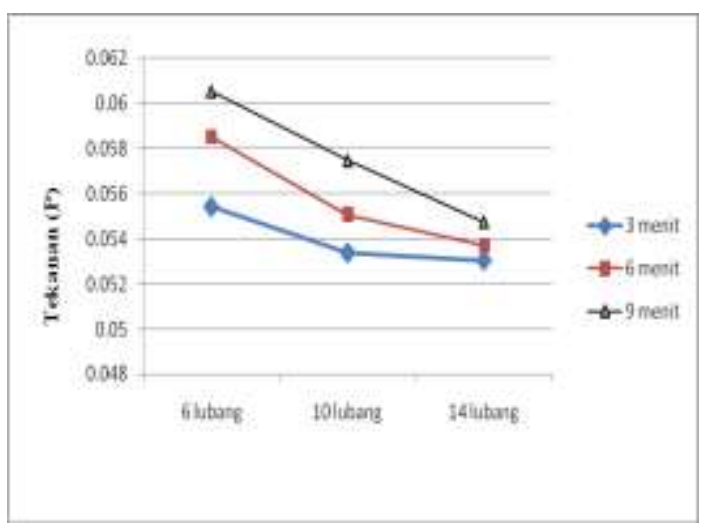

\section{Gambar 9. Grafik hubungan jumlah}

lubang pipa isap terhadap tekanan (P) untuk Q1

Tabel 8. Hubungan antarajumlah lubang pipa isap terhadap tekanan $(\mathrm{P})$ untuk $\mathrm{Q} 2$

\begin{tabular}{|c|c|c|c|}
\hline $\mathrm{N}_{0}$ & Jumlah Lubang Pipa Isap & $\begin{array}{c}\text { Waktu (t) } \\
\text { (menit) }\end{array}$ & Tekanan (P) \\
\hline 1. & \multirow{3}{*}{6} & 3 & 0.06426 \\
\hline 2. & & 6 & 0.06698 \\
\hline 3. & & 9 & 0.06834 \\
\hline 4. & \multirow{3}{*}{10} & 3 & 0.06324 \\
\hline 5. & & 6 & 0.0646 \\
\hline 6. & & 9 & 0.6596 \\
\hline 7. & \multirow{3}{*}{14} & 3 & 0.06256 \\
\hline 8. & & 6 & 0.06324 \\
\hline 9. & & 9 & 0.0646 \\
\hline
\end{tabular}

Sumber : Hasil Perhitungan 


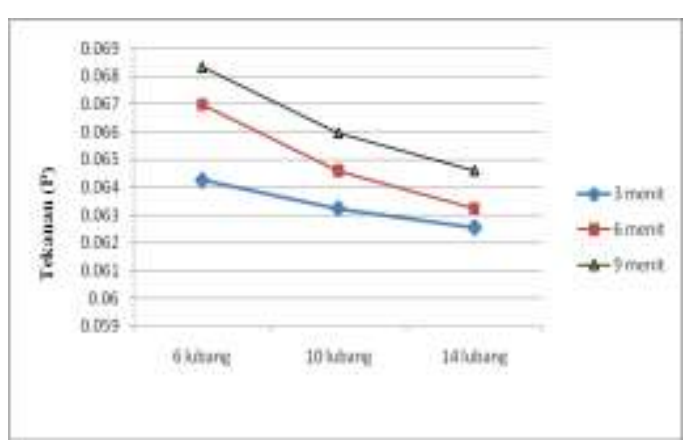

Gambar 10. Grafik hubungan antara jumlah lubang pipa isap terhadap tekanan (P) untuk Q2

Tabel 9. Hubungan antara jumlah lubang pipa isap terhadap tekanan $(\mathrm{P})$ untuk Q3

\begin{tabular}{|c|c|c|c|}
\hline No & Jumlah Lubang Pipa Isap & $\begin{array}{c}\text { Waktu (t) } \\
\text { (menit) }\end{array}$ & Tekanan (P) \\
\hline 1. & \multirow{3}{*}{6} & 3 & 0.0731 \\
\hline 2. & & 6 & 0.0748 \\
\hline 3. & & 9 & 0.07616 \\
\hline 4. & \multirow{3}{*}{10} & 3 & 0.07242 \\
\hline 5. & & 6 & 0.07344 \\
\hline 6. & & 9 & 0.0748 \\
\hline 7. & \multirow{3}{*}{14} & 3 & 0.07174 \\
\hline 8. & & 6 & 0.07208 \\
\hline 9. & & 9 & 0.07276 \\
\hline
\end{tabular}

Sumber : Hasil Perhitungan

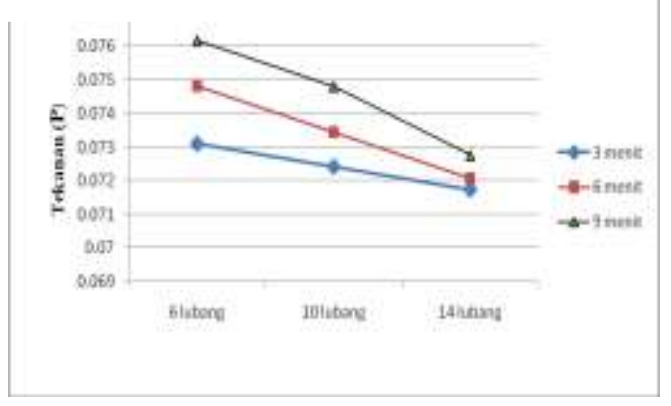

Gambar 11. Grafik hubungan antara jumlah lubang pipa isap terhadap tekanan (P) Q3.

\section{PENUTUP}

\section{Kesimpulan}

1) Pengaruh jumlah lubang pipa isap terhadap volume gelontor (Vg) yaitu semakin banyak jumlah lubang pipa isap maka semakin besar volume gelontor
(Vg), Hal ini dipengaruhi oleh tekanan (T) yang relative cukup besar untuk mengusik dan mengisap endapan sedimen kedalam pipa.

2) Pengaruh jumlah lubang pipa isap terhadap tekanan yaitu semakin banyak jumlah lubang pipa isap maka semakin kecil tekanan (P), Hal ini disebabkan oleh banyaknya jumlah lubang yang dapat mengurahi tekanan aliran dalam satuan debit tertentu.

\section{Saran}

1) Penelitian tentang penggelontoran sedimen dengan sistem flushing conduit perlu dikembangkan lebih lanjut dengan menambahkan variasi jumlah lubang untuk membandingkan data yang telah didapatkan sebelumnya.

2) Untuk penelitian selanjutnya pada saat pengambilan data perlu diperhatikan pada lubang pipa isap agar tidak mengalami penyumbatan sehingga memperoleh data yang lebih akurat.

\section{DAFTAR PUSTAKA}

Alimuddin L, Aisyah. (2012). Pendugaan Sedimentasi Pada DAS Mamasa di Kabupaten Mamasa Profinsi Sulawesi Barat.

Amrullah, Afni Mansyur Nur, dan Nurlia. (2017). Studi Pengaruh Spasi Lubang Flushing Conduit Terhadap Volume Gelontor Pada Sedimentasi Di Waduk (Uji Eksperimental)

Amrullah.(2011). Studi kinerja flushing conduit sebagai alat penguras 
endapan sedimen muara dengan exprimen Laboratorim. Program Pascasarjana Universitas Hasanuddin.Makassar.

Amrullah, Dudung Massora Alfin Eko, dan Syakir Muhammad. (2017). Studi Pengaruh Debit Penghisapan Flushing Conduit Terhadap Penggelontoran Sedimen Di Waduk (Uji Eksperimental).

Amrullah, Mardiana, dan Wahyuni Sri. (2017). Studi Pengaruh Diameter Lubang Flushing Conduit Terhadap Penggelontoran Sedimen Di Waduk (Uji Eksperimental).

Amrullah, Nisa Husnun, dan Jaya $\mathrm{T}$ Hendra. (2017). Studi Pengaruh Ketebalan Sedimen pada flushing conduit Terhadap Volume Penggelontoran dengan Material Dasar Pasir Halus diwaduk (uji Eksperimental)

Asdak, Chay. (2010). Hidrologi dan Pengelolaan Daerah Aliran Sungai: Edisi Revisi kelima.Yogyakarta: Gadjah mada Press Yogyakarta.

Darmawan B.D.(2003). Perbaikan Bentuk Lubang Perforasi Untuk Mencegah Masuknya Sedimen Ke Pipa Fluidasi. Tugas Akhir Jurusan Sipil UGM. Yogyakarta

Dahuri, R. dkk.2008. Pengelolaan Sumber Daya Wilayah Pesisir dan Lautan Secara Terpadu.PT.Pradya Paramita:Jakarta.

Hakim,Siti Riskayanti.(2015).Studi Laju Sedimentasi Waduk Bili-Bili Pasca Pengembangan Bangunan Penahan Sedimen.Fakultas Teknik Universitas Hasanuddin Makassar.
Klaas,D.(2009).Desain Jaringan Pipa Prinsip Dasar dan Aflikasi.Bandung: CV.Mandar Maju.

Krisetyana,Hari.2008.“Tingkat Efisisensi Penggelontoran Endapan Sedimen di Waduk PLTA PB.Sudirman".Jurnal.Program Pascasarjana.Universitas Diponegoro.Semarang.

Kurniawan,Aldoko Fajar.(2016).Analisa Sebaran Sedimen dan Efektivitas Tampungan Mengggunakan Teknik Interpolasi Ruang (Studi Kasus Penggelontoran Waduk Wlingi dan Waduk Lodoyo). Malang : Jurnal Ilmiah Teknik Pengairan Konsentrasi Sistem Imformasi Sumber daya Air. Universitas Brawijaya.

Lubis, Astika Murni. (2016). Analisis sedimentasi sungai way Besar. Fakultas Teknik Universitas Lampung.

Muchsin. Dan Subygo,Rachmat. (2011). Kaji Eksperimental Koefisien Kerugian Pada Percabangan Pipa Dengan Sudut $45^{\circ}, 60^{\circ}$ dan $90^{\circ}$. Jurusan Teknik Mesin Fakultas Teknik Universitas Tadulako

Nayyar, M.L. 2000.Piping Handbook (Seventh Edition). McGraw - New York, United State of America. (File pdf)

Suroso. Dan Widiyanto, wahyu. (2009). Model Pengendalian Sedimentasi Waduk Mrica dengan Fluida. Program Studi Teknik Sipil Unsoed. Purwokerto Indonesia 
Volume 11 Nomor 2, Agustus 2018

Thaha, A. (2006). Sistem Fluiasi untuk Rekayasa Pemeliharaan Alur. Universitas Gajah maa. Yogyakarta

Triatmojo B, 1993. Hidraulika II. Beta Ofset. Yogyakarta

Triatmodjo B, 1993. Hidraulik II. Beta Offise. Yogyakarta 